\title{
Examination of ${ }^{11} \mathrm{C}$-Methionine Metabolism by the Standardized Uptake Value in the Normal Brain of Children
}

\author{
Takashi Nagata, Naohiro Tsuyuguchi, Takehiro Uda, Yuzo Terakawa, Toshihiro Takami, and Kenji Ohata \\ Department of Neurosurgery, Osaka City University Graduate School of Medicine, Osaka, Japan
}

\begin{abstract}
The aim of this study was to determine the uptake of L[methyl- $\left.{ }^{11} \mathrm{C}\right]-$ methionine $\left({ }^{11} \mathrm{C}-\mathrm{MET}\right)$ in the normal brain of patients younger than $20 \mathrm{y}$, to facilitate more accurate diagnoses in young patients. Methods: Eighty-two patients were categorized into 4 groups according to their age. They underwent ${ }^{11} \mathrm{C}-\mathrm{MET}$ PET, and a standardized uptake value (SUV) was determined for different brain regions including the frontal lobe, parietal lobe, cerebellum, and brain stem. Results: Compared with all other parts of the brain, the cerebellum had the highest SUV. A tendency for a positive relationship between SUV and age was found in all regions, and a significant relationship with SUV was found in the frontal lobe and cerebellum. Conclusion: The character of SUV in the normal brains of children is different from that of adults, and these normal SUV data will play an important role as a critical reference value.
\end{abstract}

Key Words: ${ }^{11} \mathrm{C}$-methionine PET; normal accumulation; standardized uptake value; children

J Nucl Med 2011; 52:201-205

DOI: 10.2967/jnumed.110.082875

$\mathbf{T}$ he tracer $\mathrm{L}$-[methyl- $\left.{ }^{11} \mathrm{C}\right]$-methionine $\left({ }^{11} \mathrm{C}\right.$-MET) is useful for PET in neurooncology $(1,2)$, making it possible to assess the characteristics of lesions that could not be diagnosed by other means $(1,3-7) .{ }^{11} \mathrm{C}-\mathrm{MET}$ uptake is also informative about the malignancy of lesions, as is ${ }^{18} \mathrm{~F}-\mathrm{FDG}$ PET $(6,7)$. For younger patients, it is critical to get accurate information about lesions, such as the degree of malignancy and extent of lesions, as early as possible. Therefore, it is essential to have an accurate understanding of ${ }^{11} \mathrm{C}$-MET PET data. To date, ${ }^{11} \mathrm{C}-\mathrm{MET}$ PET has been interpreted mainly using the lesion-to-normal $(\mathrm{L} / \mathrm{N})$ ratio-comparison between ${ }^{11} \mathrm{C}$-MET uptake in the lesion and that in the corresponding normal region in the contralateral hemisphere (8-10). In cases of a highly malignant lesion, it would be relatively easy to point out where the lesion is, but when the disease has low malignancy, it may be difficult because

Received Aug. 31, 2010; revision accepted Oct. 21, 2010.

For correspondence or reprints contact: Takashi Nagata, 1-4-3 Asahimachi, Abeno-ku, Osaka, Japan 545-8585.

E-mail: tnagatam.0222512.ns@gmail.com

COPYRIGHT @ 2011 by the Society of Nuclear Medicine, Inc. interpretation of the result is semiquantitative. Thus, an absolute index is desirable. Uda et al. determined the normal ${ }^{11} \mathrm{C}-\mathrm{MET}$ uptake and extent of variation (11), but there is no report about normal uptake among children. In the current study, we evaluated normal ${ }^{11} \mathrm{C}$-MET uptake in persons younger than $20 \mathrm{y}$.

\section{MATERIALS AND METHODS}

\section{Patients}

Between February 1994 and May 2008, 1,228 patients underwent ${ }^{11} \mathrm{C}$-MET PET at Osaka City University Hospital. Of these patients, 136 were $20 \mathrm{y}$ or younger. Exclusion criteria included the following: infiltrative grade II-IV neoplasm according to the World Health Organization classification (12), extramedullary or midline tumors greater than $20 \mathrm{~mm}$ in diameter (3 patients), edematous changes in the brain ( 3 patients), and history of radiation therapy or chemotherapy (48 patients). The remaining 82 patients ( 40 male and 42 female; mean age $\pm \mathrm{SD}, 12.4 \pm 6.1 \mathrm{y}$; range, 0 $20 \mathrm{y}$ ), who were not taking any drugs that could influence brain metabolism, were divided into 4 groups according to their age: group 1, 0-5 y; group 2, 6-10 y; group 3, 11-15 y; and group 4, 16-20 y. The standardized uptake value (SUV) of normal brains was examined according to age and each region, including the frontal lobe, parietal lobe, cerebellum, and brain stem.

The Ethics Committee of Osaka City University Graduate School of Medicine approved this PET study. Informed consent was obtained from all patients or their parents.

\section{PET}

PET was performed with an Eminence B PET scanner (Shimadzu); the spatial resolution was $4.5 \mathrm{~mm}$ (in full width at half maximum), and slice thickness was $5.6 \mathrm{~mm}$. Scans were obtained parallel to the orbitomeatal line of the patients. After $4 \mathrm{~h}$ of fasting, ${ }^{11} \mathrm{C}-\mathrm{MET}(6 \mathrm{MBq} / \mathrm{kg})$ was injected intravenously over 30 s. After a transmission scan was obtained, a static scan of 10 min was begun 20 min after injection.

\section{Imaging Analysis}

Two experienced nuclear medicine radiologists interpreted the scans. The PET images were reconstructed by measured attenuation correction. In both analyses, the region of interest (ROI) was placed manually in the axial plane within the frontal cortex, parietal cortex, cerebellum, and brain stem (Fig. 1). The ROIs of these regions, except for the brain stem, were demarcated manually within the lateral side of the gray matter by reference to the MRI data. In the brain stem, the ROI was placed over the whole 


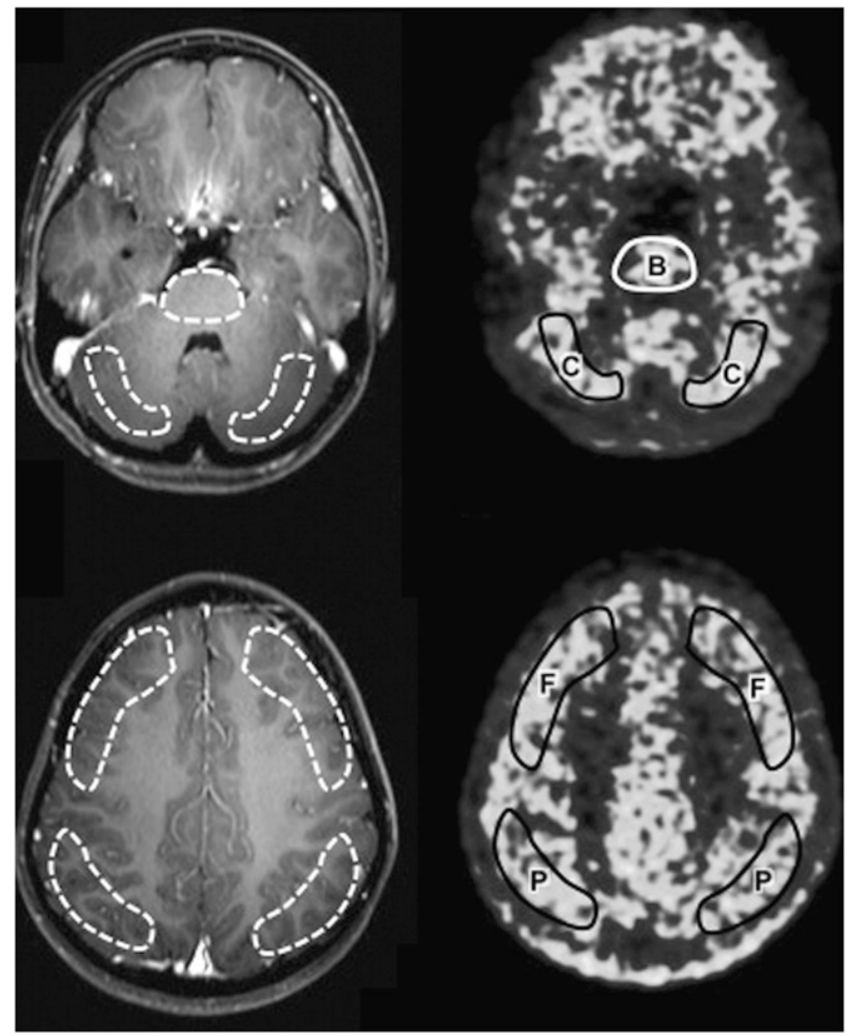

FIGURE 1. Sample of ${ }^{11} \mathrm{C}-\mathrm{MET}$ PET images. ROls were taken manually in axial plane. Coregistration between MR images and PET scans is adequate. $B=$ brain stem; $C=$ cerebellum; $F=$ frontal cortex; $\mathrm{P}=$ parietal cortex.

brain stem at the middle pons level. Mean pixel counts in the ROIs were normalized to SUV using the subject's body weight with the following equation: $\mathrm{SUV}=$ ([mean pixel count/pixel volume]/ [injected radioisotope activity/body weight] $) \times$ calibration factor.

\section{Statistical Analysis}

The differences between each part of the brain were analyzed in every group. The sample consisted of 54 patients for whom we had all SUV data, including the right frontal lobe, right parietal lobe, right cerebellum, and brain stem. Statistical analysis was performed by non-repeated-measures ANOVA, with post hoc tests corrected using Bonferroni and Student-Newman-Keuls analysis.

The relationship between SUV and age was analyzed in every part of the brain with linear regression and Spearman correlation tests. The samples used in these analyses were 158 frontal hemispheres (79 right hemispheres and 79 left hemispheres), 118 parietal hemispheres (59 right hemispheres and 59 left hemispheres), 156 cerebellar hemispheres (77 right hemispheres and 79 left hemispheres), and 62 brain stems. In all statistical analyses, significance was defined as a $P$ value less than 0.05 .

\section{RESULTS}

\section{Frontal Lobe}

SUVs (mean $\pm \mathrm{SD}$ ) in the frontal lobe were $1.133 \pm$ 0.295 and $1.088 \pm 0.379$ in group $1,1.067 \pm 0.264$ in group 2, $1.101 \pm 0.268$ in group 3 , and $1.199 \pm 0.258$ in group 4 (Table 1). A significant linear regression between SUV and age $(P=0.0282)$ was found (Fig. 2$)$.

\section{Parietal Lobe}

SUVs (mean $\pm \mathrm{SD}$ ) in the frontal lobe were $1.149 \pm$ 0.290 and $1.052 \pm 0.399$ in group $1,1.114 \pm 0.209$ in group 2, $1.122 \pm 0.220$ in group 3, and $1.235 \pm 0.243$ in group 4 (Table 1). Significant differences between groups 1 and $4(P<0.01)$ were found, but no significant linear regression between SUV and age $(P=0.396)$ was found (Fig. 2).

\section{Cerebellum}

SUVs (mean $\pm \mathrm{SD}$ ) in the frontal lobe were $1.312 \pm$ 0.309 and $1.145 \pm 0.347$ in group $1,1.319 \pm 0.345$ in group 2, $1.327 \pm 0.301$ in group 3, and $1.394 \pm 0.251$ in group 4 (Table 1). Significant differences between groups 1 and $2(P<0.05)$, groups 1 and $3(P<0.01)$, and groups 1 and $4(P<0.01)$ were found. A significant linear regression between SUV and age ( $P=0.00197)$ was also found (Fig. 2$)$.

\section{Brain Stem}

SUVs (mean \pm SD) in the frontal lobe were $1.245 \pm$ 0.306 and $1.096 \pm 0.367$ in group $1,1.222 \pm 0.165$ in group 2, $1.268 \pm 0.3422$ in group 3, and $1.298 \pm 0.265$ in group 4 (Table 1). No statistically significant difference between SUV and age was found (Fig. 2).

\section{Comparison Between Each Part of Brain}

Fifty-four of the 82 patients were analyzed, and significant differences between the frontal lobe and cerebellum $(P<0.01)$, frontal lobe and brain stem $(P<0.01)$, parietal lobe and cerebellum $(P<0.05)$, and parietal lobe and brain stem $(P<0.05)$ were found (Fig. 3). In group 3, significant

TABLE 1

SUV in Each Part of Brain in Every Group

\begin{tabular}{|c|c|c|c|c|c|c|c|c|}
\hline \multirow[b]{2}{*}{ Group } & \multicolumn{2}{|c|}{ Frontal lobe } & \multicolumn{2}{|c|}{ Parietal lobe } & \multicolumn{2}{|c|}{ Cerebellum } & \multicolumn{2}{|r|}{ Brain stem } \\
\hline & $n$ & Mean $\pm S D$ & $n$ & Mean $\pm S D$ & $n$ & Mean $\pm S D$ & $n$ & Mean $\pm S D$ \\
\hline 1 & 36 & $1.088 \pm 0.379$ & 30 & $1.052 \pm 0.399$ & 35 & $1.145 \pm 0.347$ & 11 & $1.096 \pm 0.367$ \\
\hline 2 & 14 & $1.067 \pm 0.264$ & 12 & $1.114 \pm 0.209$ & 12 & $1.319 \pm 0.345$ & 6 & $1.222 \pm 0.165$ \\
\hline 3 & 46 & $1.101 \pm 0.268$ & 28 & $1.122 \pm 0.220$ & 46 & $1.327 \pm 0.301$ & 20 & $1.268 \pm 0.3422$ \\
\hline 4 & 62 & $1.199 \pm 0.258$ & 48 & $1.235 \pm 0.243$ & 63 & $1.394 \pm 0.251$ & 25 & $1.298 \pm 0.265$ \\
\hline Total & $\begin{array}{c}158 \text { (right, 79; } \\
\text { left, 79) }\end{array}$ & $1.133 \pm 0.295$ & $\begin{array}{c}118 \text { (right, 59; } \\
\text { left, 59) }\end{array}$ & $1.149 \pm 0.290$ & $\begin{array}{c}156 \text { (right, 77; } \\
\text { left, 79) }\end{array}$ & $1.312 \pm 0.309$ & 62 & $1.245 \pm 0.306$ \\
\hline
\end{tabular}




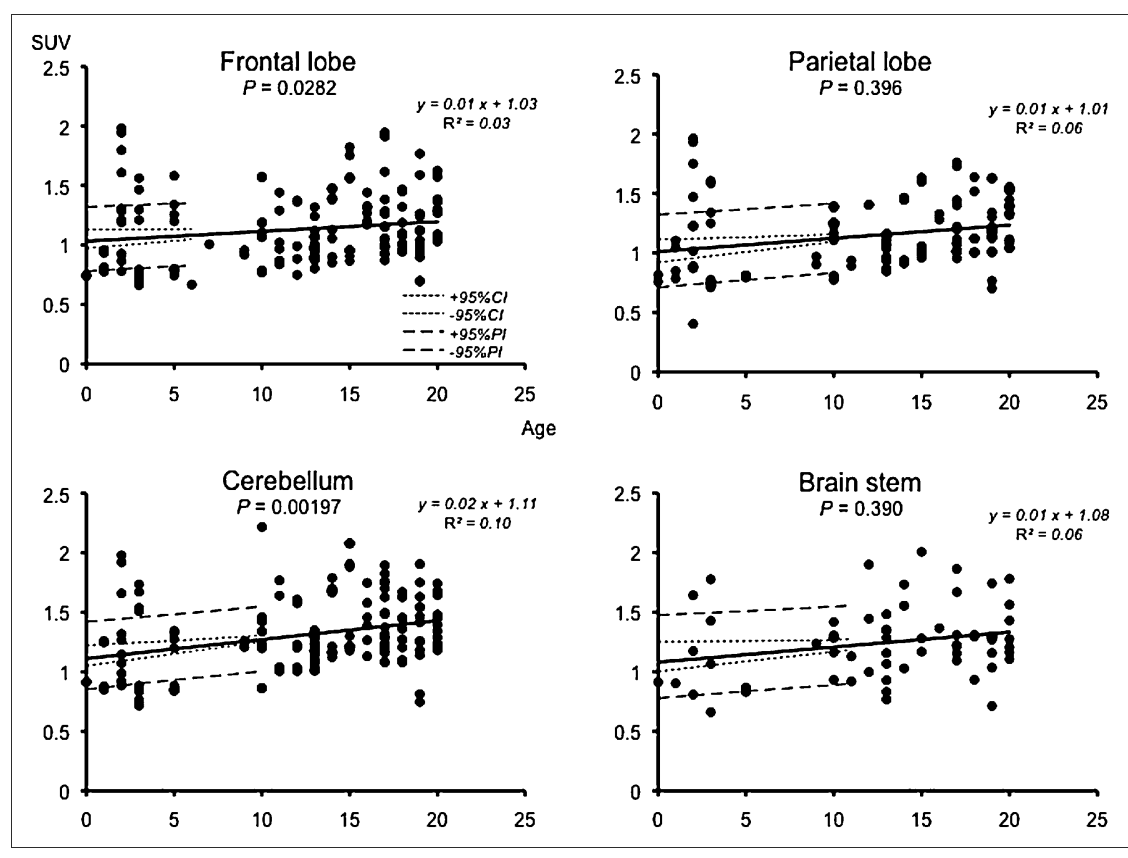

FIGURE 2. Regression and scatterplots for analysis of age-associated SUV change in frontal lobe, parietal lobe, cerebellum, and brain stem. In all parts of brain, positive linear regression was found, but $P$ value of regression coefficient was statistically significant only in frontal lobe and cerebellum. differences between the frontal lobe and cerebellum $(P<$ $0.01)$ and frontal lobe and brain stem $(P<0.01)$ were found. But in groups 1,2 , and 4 , there was no significant difference between each part of the brain (Fig. 4).

\section{DISCUSSION}

${ }^{11} \mathrm{C}$-MET PET has been used for the description of lesions and for less invasive evaluation of malignancy. Many papers show that PET is more sensitive and specific than MRI in detecting intracranial tumors $(6,9,10)$, because

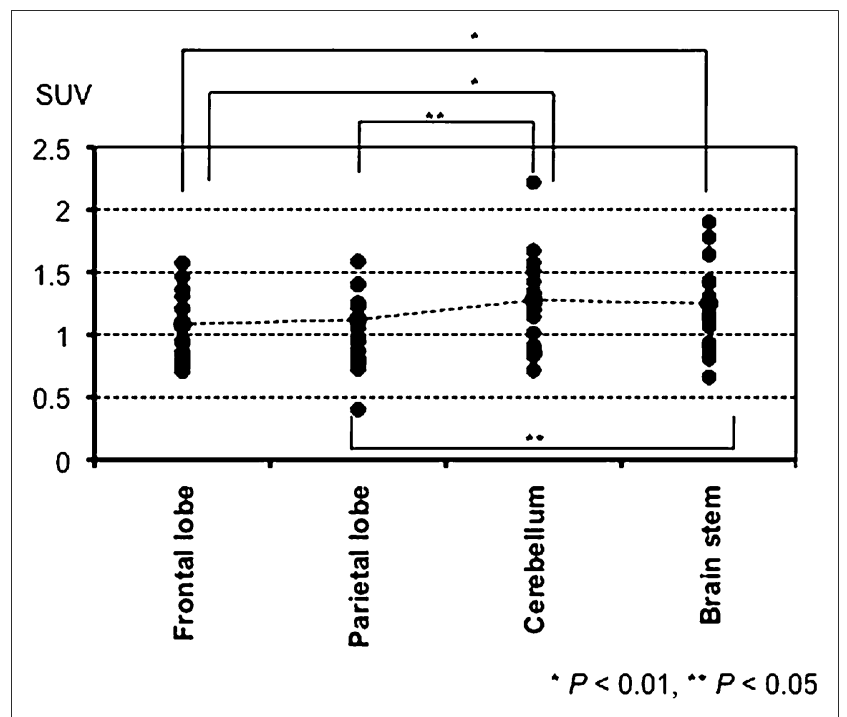

FIGURE 3. SUV in different parts of brain among patients aged 0 $20 \mathrm{y}$. Significant differences between frontal lobe and cerebellum, frontal lobe and brain stem, parietal lobe and cerebellum, and parietal lobe and brain stem were observed.
PET can detect amino acid metabolism in various cells directly. In general, amino acid metabolism is low in normal brain tissue and high in tumor tissue. According to this difference in ${ }^{11} \mathrm{C}$-MET accumulation, ${ }^{11} \mathrm{C}$-MET PET can display clear contrast images for lesions. Therefore, ${ }^{11} \mathrm{C}$ MET PET would be an informative modality for detecting the boundary between an active lesion and normal brain tissue (6). Some reports have also described ${ }^{18} \mathrm{~F}-\mathrm{FDG}$ PET as being helpful in assessing the degree of malignancy (3-6), and ${ }^{11}$ C-MET PET is also associated with malignancy and may provide valuable information on clinical tumor aggressiveness and prognosis $(6,7,13)$.

In general, ${ }^{11} \mathrm{C}$-MET PET images have been evaluated mainly by using an $\mathrm{L} / \mathrm{N}$ ratio that compares ${ }^{11} \mathrm{C}$-MET uptake in the lesion with that in the corresponding normal region in the contralateral hemisphere $(8-10)$. Because the reference normal tissue will influence the result of the $\mathrm{L} / \mathrm{N}$ ratio as a denominator, it is important that an appropriate location be chosen for the ROI used to calculate the normal reference value (14).

There are variations in normal ${ }^{11} \mathrm{C}$-MET accumulation for each part of the brain and variation between different ages (11). The reliability of the $\mathrm{L} / \mathrm{N}$ ratio will, then, decline when uptake in the lesion is not so high. In addition, in the case of tumors near the midline or brain stem, it will be difficult to set normal ROIs in the contralateral region. Therefore, it is important to know the absolute amount of SUVs in the normal brain.

In a previous study, Uda et al. reported the SUV in the normal adult brain (11), and such data are an important indicator of amino acid metabolism. To date, there has been no report about normal uptake of ${ }^{11} \mathrm{C}-\mathrm{MET}$ in brains throughout development, including infancy, childhood, and 
FIGURE 4. SUV in different brain parts in every group. In group 1, SUV was highest in brain stem, followed by cerebellum, but significant difference was not observed. In group 2, SUV was highest in cerebellum but also was not statistically significantly different from other regions. In group 3, significant differences between frontal lobe and cerebellum and frontal lobe and brain stem were found. In group 4, although SUV was highest in cerebellum, difference was not statistically significant. ${ }^{\star} P<0.01$.

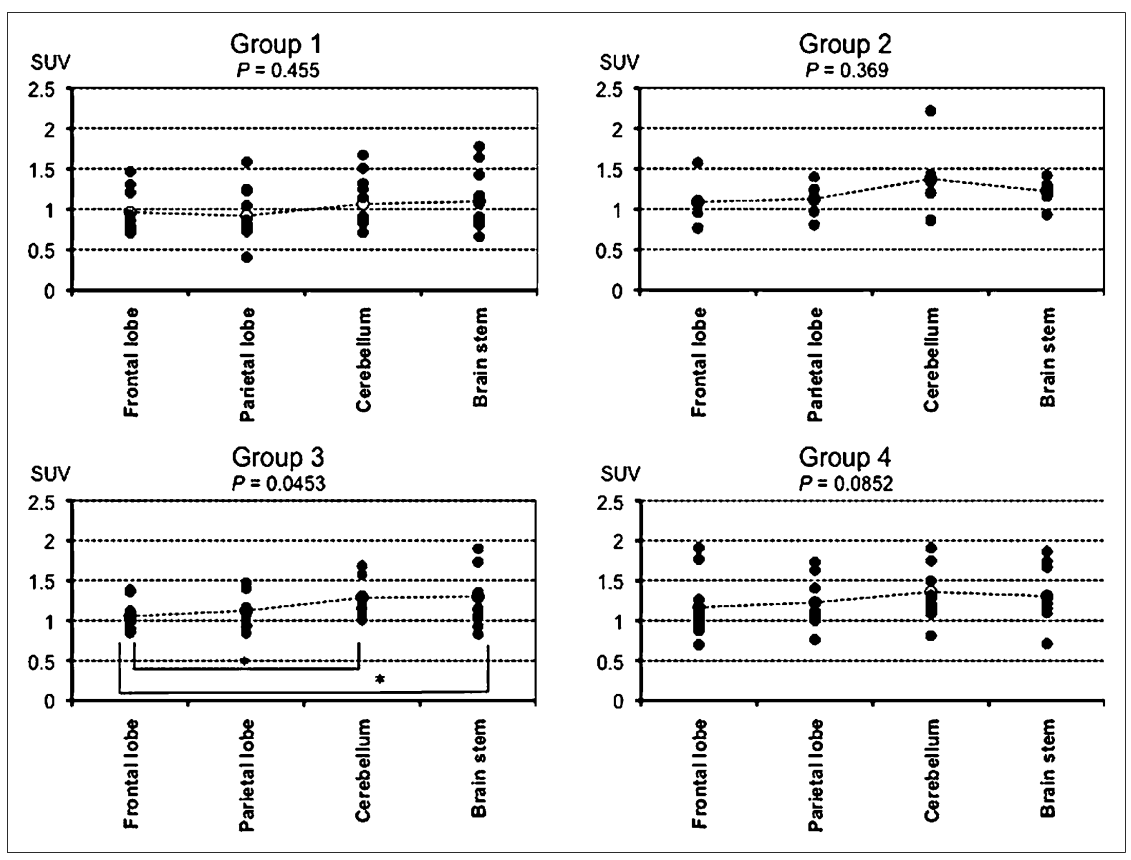

young adulthood. If standard amino acid metabolism varies by age, the SUV may be a more suitable indicator than the L/ $\mathrm{N}$ ratio in ${ }^{11} \mathrm{C}$-MET PET.

In previous reports, O'Tuama et al. showed a significant age-dependent decline of ${ }^{11} \mathrm{C}$-MET uptake in maturing adults (15), and Uda et al. also reported a slightly negative linear regression, although no statistically significant difference was observed (11). The reason for this age-associated decline in ${ }^{11} \mathrm{C}$-MET uptake was explained as a developmental decline in the activity of the neutral amino acid transporter of the blood-brain barrier (15). In the present study, we found that uptake of ${ }^{11} \mathrm{C}$-MET in all parts of the brain we studied gradually increased with age until $20 \mathrm{y}$, possibly reflecting high activity of the neutral amino acid transporter and brain protein synthesis to meet the needs of brain metabolism. These results suggest that the brains of younger persons are immature and still developing.

On the other hand, ${ }^{18}$ F-FDG PET, the local cerebral metabolic rate for glucose, is higher in infants at 3-5 mo old $(16,17)$. This tendency is different from our result in ${ }^{11} \mathrm{C}$ MET PET because the metabolism of glucose represents not only the activity of neurocytes but also the activity of the neural network, including structures around synapses, whereas amino acid metabolism indicates the extent of protein synthesis. ${ }^{11} \mathrm{C}$-MET uptake also increases linearly as the brain matures during young adulthood. After brain weight reaches a plateau, the uptake begins to decrease, reflecting developmental decline, as described in a previous report (15).

In each part of the brain, SUV was highest in the cerebellum in this population, similar to results reported for adult humans investigated by Uda et al. (11). The plasticity of synapses is important for motor learning (18), which is critically governed by the cerebellum. Activity of the neural network will increase amino acid metabolism in neurocytes, and this higher motor learning will continue for a lifetime. In addition, there is higher cell density in the cerebellum, especially in the granular cell layer, than is found in other brain regions. Therefore, total amino acid metabolism will increase. These are possible reasons for high accumulation in the cerebellum.

We obtained more reliable information about ${ }^{11} \mathrm{C}$-MET SUV in normal brains, including age-associated and regional changes. This study provides useful information for clinical determinations such as operative indications, which are affected by the malignancy of the lesion.

When continuous long-term follow-up is necessary in some children and younger patients, information about normal metabolism variation associated with aging is useful in making judgments regarding the effectiveness of treatment, and thus it is essential to make accurate evaluations according to a patient's age and brain region.

\section{CONCLUSION}

The present study evaluated the accumulation of ${ }^{11} \mathrm{C}$ MET and SUVs in the normal brain among children and young adults and found significant age-associated differences in some regions. To make more accurate evaluations in ${ }^{11} \mathrm{C}$-MET PET, age-associated criteria will be necessary in children and young adults.

\section{REFERENCES}

1. De Witte O, Goldberg I, Wikler D, et al. Positron emission tomography with injection of methionine as a prognostic factor in glioma. J Neurosurg. 2001;95: 746-750.

2. Kato T, Shinoda J, Oka N, et al. Analysis of ${ }^{11} \mathrm{C}$-methionine uptake in low-grade gliomas and correlation with proliferative activity. AJNR. 2008;29:1867-1871. 
3. Goldman S, Levivier M, Pirotte B, et al. Regional methionine and glucose uptake in high-grade gliomas: a comparative study on PET-guided stereotactic biopsy. J Nucl Med. 1997;38:1459-1462.

4. Kaschten B, Stevenaert A, Sadzot B, et al. Preoperative evaluation of 54 gliomas by PET with fluorine-18-fluorodeoxyglucose and/or carbon-II-methionine. J Nucl Med. 1998;39:778-785.

5. Levivier M, Massager N, Wikler D, et al. Use of stereotactic PET images in dosimetry planning of radiosurgery for brain tumors: clinical experience and proposed classification. J Nucl Med. 2004;45:1146-1154.

6. Pirotte BJ, Lubansu A, Massager N, et al. Clinical interest of integrating positron emission tomography imaging in the workup of 55 children with incidentally diagnosed brain lesions. J Neurosurg Pediatr. 2010;5:479-485.

7. Utriainen M, Metsahonkala L, Salmi TT, et al. Metabolic characterization of childhood brain tumors: comparison of F-18-fluorodeoxyglucose and C-11-methionine positron emission tomography. Cancer. 2002;95:1376-1386.

8. Terakawa Y, Tsuyuguchi N, Iwai Y, et al. Diagnostic accuracy of ${ }^{11} \mathrm{C}$-methionine PET for differentiation of recurrent brain tumors from radiation necrosis after radiotherapy. J Nucl Med. 2008;49:694-699.

9. Tsuyuguchi N, Sunada I, Iwai Y, et al. Methionine positron emission tomography of recurrent metastatic brain tumor and radiation necrosis after stereotactic radiosurgery: is a differential diagnosis possible? J Neurosurg. 2003;98:1056-1064.

10. Tsuyuguchi N, Takami T, Sunada I, et al. Methionine positron emission tomography for differentiation of recurrent brain tumor and radiation necrosis after stereotactic radiosurgery: in malignant glioma. Ann Nucl Med. 2004;18: 291-296.

11. Uda T, Tsuyuguchi N, Terakawa Y, Takami T, Ohata K. Evaluation of the accumulation of ${ }^{11} \mathrm{C}$-methionine with standardized uptake value in the normal brain. J Nucl Med. 2010;51:219-222.

12. Louis DN, Ohgaki H, Wiestler OD, et al. The 2007 WHO classification of tumours of the central nervous system. Acta Neuropathol. 2007;114:97-109.

13. Kato T, Shinoda J, Nakayama N, et al. Metabolic assessment of gliomas using ${ }^{11} \mathrm{C}$-methionine, $\left[{ }^{18} \mathrm{~F}\right]$ fluorodeoxyglucose, and ${ }^{11} \mathrm{C}$-choline positron-emission tomography. AJNR. 2008;29:1176-1182.

14. Coope DJ, Cizek J, Eggers C, Vollmar S, Heiss WD, Herholz K. Evaluation of primary brain tumors using ${ }^{11} \mathrm{C}$-methionine PET with reference to a normal methionine uptake map. $J$ Nucl Med. 2007;48:1971-1980.

15. O'Tuama LA, Phillips PC, Smith QR, et al. L-methionine uptake by human cerebral cortex: maturation from infancy to old age. J Nucl Med. 1991;32:16-22.

16. Suhonen-Polvi H, Ruotsalainen U, Kinnala A, et al. FDG-PET in early infancy: simplified quantification methods to measure cerebral glucose-utilization. J Nucl Med. 1995;36:1249-1254.

17. Chugani HT, Phelps ME. Maturational changes in cerebral function in infants determined by ${ }^{18}$ F-FDG positron emission tomography. Science. 1986;231:840 843.

18. Boyden ES, Katoh A, Raymond JL. Cerebellum-dependent learning: the role of multiple plasticity mechanisms. Annu Rev Neurosci. 2004;27:581-609. 